\title{
Repellent effect of the caraway Carum carvi L. on the rice weevil Sitophilus oryzae L. (Coleoptera, Curculionidae)
}

\section{Małgorzata Kłyś}

Uniwersytet Pedagogiczny im Komisji Edukacji Narodowej w Krakowie

Aleksandra Izdebska ( $\sim$ olaleksandra7@gmail.com )

Uniwersytet Pedagogiczny im Komisji Edukacji Narodowej w Krakowie https://orcid.org/0000-00015612-8060

\section{Natalia Malejky-Kłusek}

Uniwersytet Pedagogiczny im Komisji Edukacji Narodowej w Krakowie

\section{Research note}

Keywords: essential oil, insecticides, L-carvone, repellence, storage pests

Posted Date: September 24th, 2020

DOI: https://doi.org/10.21203/rs.3.rs-33914/v2

License: (c) (i) This work is licensed under a Creative Commons Attribution 4.0 International License.

Read Full License 
1 Repellent effect of the caraway Carum carvi L. on the rice weevil Sitophilus oryzae L.

2 (Coleoptera, Curculionidae)

3

4 Małgorzata Kłyś $^{1}$, Aleksandra Izdebska $^{1^{*}}$, Natalia Malejky-Kłusek ${ }^{1}$

5

$6{ }^{1}$ Pedagogical University of Cracow, Institute of Biology, Department of Ecology and

7 Environmental Protection, Podchorążych 2, 30-084 Kraków, Poland

$8 \quad$ e-mail: malgorzata.klys@up.krakow.pl

9 e-mail: olaleksandra7@gmail.com

10 e-mail: natalia.malejky@o2.pl

$11 *$ corresponding author 


\section{Abstract}

\section{Objective}

14 The aim of the study was to check whether Carum carvi L. essential oil and L-carvone act on

15 Sitophilus oryzae L. as repellents and/or insecticides, in what concentrations and after what time.

\section{Results}

17 Caraway essential oil and L-carvone the highest repellency showed not in the highest

18 concentrations used in the tests (1\%), but in lower concentrations, respectively $0.5 \%$ and $0.1 \%$.

19 Caraway essential oil in all used concentrations showed repellent effects on S. oryzae. The

20 highest repellency (60-98\%) caused caraway essential oil in concentration $0.5 \%$ after $1,2,3,4$

21 and $5 \mathrm{~h}$ of the research. The highest repellence of L-carvone (16-100\%) resulted in concentration

$220.1 \%$. The highest mortality of $S$. oryzae caused $0.5 \%$ caraway essential oil.

24 Key words: essential oil, insecticides, L-carvone, repellence, storage pests.

\section{Introduction}

27 It is expected that by 2050 the number of people in the world will increase to 9.1 billion and that 28 to feed that number an additional $70 \%$ increase in food production will be needed $[1,2,3]$.

The losses in world food production are enormous. At each stage of production, from

30 producers to consumers, there are losses that constitute enormous "chain of losses". It is

31 estimated that 30-50\% of produced food is lost each year [4]. Gitonga et al. [5] and Lesk et al.

32 [6] report that biotic factors (insects, mites, rodents, and fungi) and abiotic factors (temperature,

33 humidity) cause losses in total harvest reaching even up to $60 \%$. A large number of publications

34 indicate that the greatest losses are incurred during storage, particularly in developing countries 
$35[7,8,9,10]$. In developed countries, the over-production of food is frequent, and storing the 36 surpluses creates favourable conditions for the development of pests. Every year, only during

37 storage, 5-10\% of produced food is lost [4]. As reported by Kumar and Kalita [10], as much as 50

$38-60 \%$ of cereal grains can be destroyed during storage, principally because of technical

39 inefficiency.

40 It is said that the insect pest are responsible for huge losses in stored grain $[11,12,13]$.

41 Over 20 thousand species of field and storage pests are responsible for destroying approx. one-

42 third of the world food production [14]. One of such dangerous pest of stored cereal grain, e.g.,

43 wheat, maize, and rice, is Sitophilus oryzae $[15,16]$. These insects bring about the reduction in

44 germination capacity, reduction in nutritive value, and the changes in chemical composition of

45 grains, etc.

46 The application of synthetic chemical insecticides rises a number of doubts associated with

47 their adverse effects upon the environment and human health $[14,17,18,19]$. Using natural

48 products are effective and simultaneously friendly to the environment. Such substances include

49 powders, oils, and extracts from plants [17, 20, 21].

50 The objective of the presented study was to assess the efficacy of the essential oil from

51 common caraway and of L-carvone, which is a compound extracted from it, upon the mortality

52 and emigration (repellence) towards S. oryzae. Whether the caraway essential oil and L-carvone

53 affect S. oryzae as insecticides and/or repellents, the required concentrations and times of

54 application were assessed.

\section{Main text}


59 The studies were conducted in laboratory conditions at $29^{\circ} \pm 1^{\circ} \mathrm{C}$ with $60 \pm 5 \%$ relative humidity

60 (RH). Ten-day old, adult beetles of S. oryzae used in the tests were obtained from breeding

61 colonies kept under the same conditions as experimental colonies. In the tests for repellence, the

62 methodology pertaining to emigration (repellence) developed by Kłyś [21, 23]. Sets containing

63 two plastic breeding containers were used: an inside container with $28 \mathrm{~cm}^{2}$ of floor area, and an

64 outside container with $50 \mathrm{~cm}^{2}$ floor area. Forty grams of wheat grain were placed in each

65 container. The inside container had 30 holes of $1.5 \mathrm{~mm}$ in diameter separated by $1.5 \mathrm{~cm}$ spaces in

66 the floor and sidewalls up to the level of grain. Four 4-cm high "screw inserts" were mounted

67 onto the bottom of the inside container allowing the placement of the container above wheat grain

68 in the outside container that prevented migrating beetles from returning to the inside container

69 [21]. The insects were placed in the inside container together with a circular ring of filter paper

70 soaked with the caraway essential oil in the subsequent series of mass concentrations of $0.1 \%$,

$710.5 \%$, and $1 \%$, and of L-carvone in $0.05 \%, 0.1 \%, 0.5 \%$, and $1 \%$ concentrations. The caraway oil

72 and L-carvone were bought from Sigma-Aldrich. The repellent effect, mortality, and the numbers

73 of insects were recorded after 1, 2, 3, 4, 24, and 48 hours. Each variant of the experiment was

74 conducted in nine repetitions.

The estimates of repellent effects were based on the emigration index calculated as a percentage proportion of individuals emigrating compared with the total number of individuals in

77 the population. The calculations were made using the following formula: 
$81 \bar{x}_{\mathrm{el}}$ - mean number of live migrants

$82 \bar{x}_{\text {ed }}$ - mean number of dead migrants

$83 \bar{x}_{1}-$ mean number of live individuals in both containers

$84 \bar{x}_{\mathrm{d}}-$ mean number of dead individuals in both containers

85 The mortality index is the percentage proportion of dead individuals compared with the total

86 number of individuals at a given time. It was calculated from the following formula [24]:

$$
\frac{\bar{x}_{d}}{\bar{x}_{d}+\bar{x}_{l}} \cdot 100 \%
$$

90 where:

$91 \bar{x}_{\mathrm{d}}-$ mean number of dead insects

$92 \bar{x}_{1}-$ mean number of live insects

93 We have investigated whether there are statistically significant differences in the repellent 94 effect of different concentrations of essential caraway oil and L-carvone on S. oryzae. The

95 dependent variable is the insect emigration rate. Since the distribution of data in particular groups

96 separated according to the concentration of the substances examined significantly differed from

97 normal distribution (Shapiro-Wilk test, $\mathrm{p}<0.05$ ), the ANOVA Kruskall-Wallis rank test was

98 applied, followed by a multiple comparison test [25]. The test probability level "p" and the

99 significance level " $\alpha$ " were 0.05 . The calculations were performed in the Statistica 13.3 program. 


\section{Results}

102 The caraway essential oil applied in all concentrations used $(0.1,0.5,1 \%)$ resulted in a major repellent effect towards S. oryzae. After 1, 2, 3, and 4 hours of study, the strongest repellence was

104 confirmed by the highest values of migration index, fluctuating from 60 to $98 \%$, was caused by 105 the essential oil at $0.5 \%$ concentration. In the control culture, the simultaneous emigration index

106 fluctuated between 2 to $9 \%$. After 24 and 48 hours, the caraway essential oil in all used concentrations resulted in very high emigration (repellence) among rice weevils. At that time, in the control culture, it amounted to only $13-19 \%$. It was interesting to see that the highest repellence to $S$. oryzae in the initial four hours of studies was exerted in both the highest concentration applied and in a lower one, i.e. $0.5 \%$ (Fig. 1). A similar relationship was noted

111 during the use of L-carvone; a $0.1 \%$ concentration resulted in the highest emigration of beetles 112 (from 16 to $100 \%$ ) in each of the analysed time intervals. The subsequently lower repellence (9$11338 \%$ ) was showed by L-carvone at a $0.5 \%$ concentration, and then only after 1, 2, 3, and 4 hours, 114 at $1 \%$ concentration $(7-22 \%)$ (Fig. 2). Analyzing the emigration results using the ANOVA Kruskall-Wallis test, statistically

116 significant differences were found between the emigration of $S$. oryzae in the control culture and 117 the emigration in the cultures with the addition of caraway essential oil at all concentrations and 118 time intervals. However, statistically significant differences between doses are marked with 119 asterisks in Figures 1 and 2.

At the three concentrations $(0.1,0.5$, and $1 \%)$ used in the tests, the caraway essential oil

121 caused the highest mortality among the individuals of S. oryzae when applied at $0.5 \%$

122 concentration. Statistical analysis of S. oryzae mortality results showed statistically significant

123 differences $(\mathrm{p}<0.05)$ between mortality in the control culture and the culture using caraway 124 essential oil at $0.5 \%$ concentration (from 2 to 24 hours). At concentrations of 0.1 and $1 \%$, the oil 
125 did not evoke mortality of insects throughout the initial five hours of experiments. It was only

126 after 24 hours that the mortality of the rice weevil population treated by caraway essential oil at

$127 \quad 0.5$ and $1 \%$ concentrations amounted about $100 \%$, and among the emigrants, it was very low, i.e.

128 the mortality indices fluctuated from 0.6 to $1.1 \%$ (Fig. 3). Similarly as in the case of repellence,

129 the highest mortality among $S$. oryzae was obtained after applying the caraway essential oil at the

130 concentration of $0.5 \%$, and not the highest used in the tests.

\section{Discussion}

133 A number of plant products and extracts were tested as repellents against $S$. oryzae with the use 134 of various research techniques and with variable efficacy [21]. For example, the fastest repellent 135 effect on rice weevil, after a mere 5 minutes, was exerted by the crude methanol extract of 136 Duabanga grandiflora at a $0.252 \mathrm{mg} / \mathrm{cm}^{2}$ concentration, where $63 \%$ repellence was reached.

137 After 4 hours, the efficacy of repellence against the weevil was $100 \%$ [26].

138 In their studies, however, Tripathi and Upadhyay [27] obtained the efficacy of 91.1

139 percentage repellence (PR) against adult S. oryzae, after 1 hour, when they applied leaf essential 140 oil from Hyptis suaveolens at a concentration of $9.2 \mathrm{mg} / \mathrm{cm}^{2}$.

141 Kim et al. [34] assessed the insecticide activity as well as the inhibiting effect of 142 acetylcholinesterase (AChE) by essential oils and compounds extracted from 10 species of plants 143 of the family of Apiaceae exerted on Sitophilus oryzae. Among the plants included in the study, 144 the essential oils obtained from Anethum graveolens, Carum carvi, and Cuminum cyminum 145 showed strong fumigant toxicity against S. oryzae. The plants concerned also included Carum 146 carvi. Among the compounds, (+)-carvone, (-)-carvone, cuminaldehyde, dihydrocarvone,

147 linalool oxide, carveol, trans-anethole, and neral also displayed higher toxicities against S. oryzae 
as fumigants. The strongest inhibitions towards acetylocholinoesterase were displayed by $\alpha$ -

149 pinen, followed by $\beta$-pinen and limonene.

In our study, the essential oil from Carum carvi applied at $0.5 \%$ concentration displayed

151 insecticidal action resulting in $100 \%$ mortality among S. oryzae as early as after 5 hours.

152 López et al. [35] had also studied the effects of active substances contained in the essential oils

153 obtained from C. carvi (carvon and limonene), Coriandrum sativum (linalool), and Ocimum

154 basilicum (estragol) upon the populations of S. oryzae, R. dominica, and Cryptolestes pusillus.

155 Against S. oryzae, the most effective monoterpenoid was carvon (1364ppm) in combination with 156 camphor (131ppm), where, after 24 hours, $100 \%$ of the beetles were dead. Other mixtures of 157 active substances, whose main component was caraway oil, caused high mortality in both rice 158 weevils as in the remaining two species (approx. $90-100 \%$ ). Against $S$. oryzae, the mortality index in the application of linalool (1723ppm) combined with camphor (185ppm) reached $63 \%$. Against $R$. dominica and $C$. pusillus, the mortality indexes were $96 \%$ and $100 \%$, respectively.

161 Estragol affected the activities of rice weevil in a variable and ambiguous way. The most interesting results obtained in our research include those which indicate the highest repellent effects of caraway essential oil and L-carvon upon S. oryzae in both the highest concentration applied and at the lower concentrations used, i.e. $0.5 \%$ and $0.1 \%$, respectively. The explanation of the mechanism of this phenomenon in insects requires further physiological and biochemical studies. Similar results were obtained with respect to other arthropod species, e.g., mosquitoes, biting flies, fleas, and ticks applying repellents based on DEET and permethrin.

168 DEET is a repellent with a wide spectrum of action against arthropod bites. Although the 169 protection against arthropod bites provided by DEET is proportional to the logarithm of the dose, 170 the higher concentrations of DEET ensure that the protection lasts longer; however, in the range 171 up to $50 \%$, the concentrations above $50 \%$ do not increase the efficacy of DEET [36]. Also, tests 
172 carried out on ticks showed that permethrin reduced the reproductive rate of females not at the

173 highest applied dose $(12.5 \mu \mathrm{g})$, but at a lower dose of $6.25 \mu \mathrm{g}$ [37]. Also in ticks this relationship

174 has not yet been elucidated.

175 In our research on the effect of $C$. carvi on $S$. oryzae, we also checked the effect of 176 contact, oral effects, but its effectiveness was not as high as in the case of essential oil and L177 carvon.

178 The results obtained indicate that consideration should be given to the possibility of using

179 the essential oil from Carum carvi and L-carvon in the integrated protection against S. oryzae in

180 stored cereal grains as well as in the control measures against that insect species.

182 Conclussion

183 In conclusion, the greatest repellent effects on $S$. oryzae were caused by lower doses of caraway

184 essential oil and L-carvone. Which is a new discovery among plant compounds used against 185 stored pests. This differs from the results obtained so far in relation to stored pests, in which the 186 repellency increased with increasing concentration. Similar results to our research were obtained 187 with respect to other arthropod species, e.g., mosquitoes, biting flies, fleas, and ticks applying 188 repellents based on DEET and permethrin.

189

$190 \quad$ Limitations

191 Tests are limited by the number of trials because insect counting must be done quickly to 192 maintain hourly intervals between recording data.

\section{Declarations}

195 Ethics approval and consent to participate 
196 Ethics approval.

197 Consent for publish

198 Not applicable.

199 Availability of data and materials

200 All data generated or analysed during this study are included in this published article.

201 Abbreviations

202 Not applicable.

203 Competing interests

204 The authors declare that they have no competing interests.

205 Funding

206 Not applicable.

207 Authors' contributions

208 MK concept and wrote the manuscript, compile the methodology, analysis of results. AI

209 wrote the manuscript, conducted experiments, compiled figures, collect references. NM

210 conducted experiments, collect references. All authors read and approved the manuscript.

\section{Acknowledgements}

212 Not applicable.

213

\section{References}

215 1. Godfrey HC, Beddington JR, Crute IR, Haddad L, Lawrence D, Muir JF, Pretty J, Robinson S,

216 Thomas SM, Toulmin C. Food Security. The Challenge of Feeding 9 Billion People. Science.

217 2010;327:812-818. https://doi.org/10.1126/science.1185383. 
2. Parfitt J, Barthel M, Macnaughton S. Food waste within food supply chains: quantification and

219 potential for change to 2050. Philos Trans R Soc B Biol Sci. 2010;365:3065-3081.

220 https://doi.org/10.1098/rstb.2010.0126.

221 3. Hodges RJ, Buzby JC, Bennett B. Postharvest losses and waste in developed and less

222 developed countries: opportunities to improve resource use. J Agric Sci. 2011;149:37-45.

223 https://doi.org/10.1017/S0021859610000936.

224 4. Fox T. Global Food: Waste Not, Want Not. London. Westminster: Institution of Mechanical

225 Engineers; 2013;1-31.

226 5. Gitonga ZM, De Groote H, Kassie M, Tefera T. Impact of metal silos on households' maize 227 storage, storage losses and food security: An application of a propensity score matching. Food 228 Policy. 2013;43:44-55. https://doi.org/10.1016/ j.foodpol.2013.08.005.

229 6. Lesk C, Rowhani P, Ramankutty N. Influence of extreme weather disasters on global crop 230 production. Nature. 2016;529:84-87. https://doi.org/10.1038/ nature16467.

231 7. Bala BK, Haque MA, Hossain MA, Majumdar S. Post harvest loss and technical efficiency of 232 rice, wheat and maize production system: Assessment and measures for strengthening food 233 security. Bangladesh Agricultural University. National Food policy Capacity Strengthening 234 Programme. Final Report CF. 2010;6(08).

235 8. Gustavsson J, Cederberg C, Sonesson U, van Otterdijk R, Meybeck A. Global food losses and 236 food waste - extent, causes and prevention. Rome. Italy: Food and Agriculture Organization of 237 the United Nations (FAO); 2011.

238 9. Majumder S, Bala B, Arshad FM, Haque M, Hossain M. Food security through increasing 239 technical efficiency and reducing postharvest losses of rice production systems in Bangladesh.

240 Food Secur. 2016;8:361-374. https://doi.org/10.1007/s12571-016-0558-x. 
10. Kumar D, Kalita P. Reducing Postharvest Losses during Storage of Grain Crops to

242 Strengthen Food Security in Developing Countries. Foods. 2017;6:8. http://dx.doi.org/

$243 \quad 10.3390 /$ foods6010008.

244 11. Abass AB, Ndunguru G, Mamiro P, Alenkhe B, Mlingi N, Bekunda M. Post-harvest food 245 losses in a maize-based farming system of semi-arid savannah area of Tanzania. J Stored Prod 246 Res. 2014;57:49-57. https://doi.org/10.1016/j.jspr.2013.12.004.

247 12. Chegere MJ. Post-harvest losses reduction by small-scale maize farmers: The role of handling 248 practices. Food Policy. 2018;77:103-115. https://doi.org/10.1016/j.foodpol.2018.05.001.

249 13. Yadav J, Yadav JL, Saini RK, Devi M. Stored Grain Pests Incidence in Wheat with Particular 250 Reference to Khapra Beetle, Trogoderma granarium Everts in Southern Haryana, India. Int J 251 Curr Microbiol App Sci. 2018;7:2179-2186. https://doi.org/10.20546/ijcmas.2018.703.257.

252 14. Trivedi A, Nayak N, Kumar J. Recent advances and review on use of botanicals from 253 medicinal and aromatic plants in stored grain pest management. J Entomol Zool Stud. $254 \quad 2018 ; 6: 295-300$.

255 15. Malik G, Qadir A, Khan HAA. Effect of temperature on the toxicity of biorational 256 insecticides against Sitophilus oryzae (Linnaeus) in stored wheat. Pakistan J Zool. 2018;50:1569257 1572. http://dx.doi.org/10.17582/journal.pjz/2018.50.4.sc10.

258 16. Srivastava S, Mishra G, Mishra HN. FTNIR-A robust diagnostic tool for the rapid detection 259 of Rhyzopertha dominica and Sitophilus oryzae infestation and quality changes in stored rice 260 grains. Food Bioprocess Tech. 2018;11:785-796. https://doi.org/10.1007/s11947-017-2048-3. 261 17. Shah TB, Saeed M, Khan I, Khan A, Khan GZ, Farid A, Khan SM. Repellency evaluation of 262 selected indigenous medicinal plant materials against Rhyzopertha dominica (Herbst) 263 (Coleoptera: Tenebrionidae). J Entomol Zool Stud. 2015;3:65-68. 
18. Kısa A, Akyüz M, Çoğun HY, Kordali Ş, Bozhüyük AU, Tezel B, Şiltelioğlu U, Anıl B,

265 Çakır A. Effects of Olea europaea L. leaf metabolites on the tilapia (Oreochromis niloticus) and

266 three stored pests, Sitophilus granarius, Tribolium confusum and Acanthoscelides obtectus. Rec

267 Nat Prod. 2018;12:201-215. http://doi.org/10.25135/rnp.23.17.07.126

268 19. Koutsaviti A, Antonopoulou V, Vlassi A, Antonatos S, Michaelakis A, Papachristos DP,

269 Tzakou O. Chemical composition and fumigant activity of essential oils from six plant families

270 against Sitophilus oryzae (Col: Curculionidae). J Pest Sci. 2018;91:873-886.

271 https://doi.org/10.1007/s10340-017-0934-0

272 20. Akhtar M, Arshad M, Raza ABM, Chaudhary MI, Iram N, Akhtar N, Mahmood T. Repellent

273 effects of certain plant extracts against rice weevil, Sitophilus oryzae L. (Coleoptera:

274 Curculionidae). Int J Agric Appl Sci. 2013;5:69-73.

275 21. Kłyś M, Malejky N, Nowak-Chmura M. The repellent effect of plants and their active

276 substances against the beetle storage pests. J Stored Prod Res. 2017;74:66-77.

277 https://doi.org/10.1016/j.jspr.2017.10.006.

278 22. Regnault-Roger C, Vincent C, Arnason JT. Essential oils in insect control: low-risk products

279 in a high-stakes world. Annu Rev Entomol. 2012;57:405-424. https://doi.org/10.1146/annurev-

280 ento-120710-100554

281 23. Kłyś M. The influence of the herbs sage and wormwood on the migration of Rhyzopertha

282 dominica (F.) (Coleoptera: Bostrichidae) populations. J Stored Prod Res. 2007;43:558-563.

283 https://doi.org/10.1016/j.jspr.2006.11.006.

284 24. Kłyś M. Wpływ ziół na niektóre gatunki chrząszczy szkodliwe w magazynach i

285 przechowalniach. Wydawnictwo Naukowe Uniwersytetu Pedagogicznego. Kraków: 2013;77pp.

286 (in English summary). 
25. Sokal RR, Rohlf FJ. Biometry - the principles and practice of statistics in biological research.

288 New York, USA: WH Freeman and Company. 1995;887 pp.

26. Auamcharoen W, Chandrapatya A, Kijjoa A, Kainoh Y. Toxicity and Repellency Activities

290 of the Crude Methanol Extract of Duabanga grandiflora (Lythraceae) Against Sitophilus oryzae

291 (Coleoptera: Curculionidae). Pakistan J Zool. 2012;44:227-232.

292 27. Tripathi AK, Upadhyay S. Repellent and insecticidal activities of Hyptis suaveolens

293 (Lamiaceae) leaf essential oil against four stored-grain coleopteran pests. Int J Trop Insect Sci.

294 2009;29:219-228. https://doi.org/10.1017/S1742758409990282.

295 28. Nattudurai G, Paulraj MG, Ignacimuthu S. Toddalia asiatica (L.) Lam. essential oil: A 296 potential natural fumigant and repellent against three coleopteran pests of stored products. Int J

297 Pure Appl Zool. 2014;2:246-255. https://doi.org/10.4172/2161-0983.1000148.

298 29. Nattudurai G, Irudayaraj SS, Paulraj MG, Baskar K, Ignacimuthu S. Insecticidal and

299 Repellent Activities of Toddalia asiatica (L.) Lam. Extracts against Three Major Stored Product

300 Pests. Entomol Ornithol Herpetol. 2015;4:1. https://doi.org/10.4172/2161-0983.1000148.

30. Ogendo JO et al. Bioactivity of Ocimum gratissimum L. oil and two of its constituents against

302 five insect pests attacking stored food products. J Stored Prod Res. 2008;44:328-334.

303 https://doi.org/10.1016/j.jspr.2008.02.009.

304 31. Yoon C, Kang SH, Jang SA, Kim YJ, Kim GH. Repellent Efficacy of Caraway and

305 Grapefruit Oils for Sitophilus oryzae (Coleoptera: Curculionidae). J Asia Pac Entomol. 2007;10:263-267. https://doi.org/10.1016/S1226-8615(08)60361-1.

307 32. Elgizawy KKH, El-Shewy AM, Morsy AR. Evaluation of Essential Oil and its Main Active 308 Ingredients of Chinese Litsea cubeba Against Two Stored-Grain Insects. Academic Journal of 309 Entomology. 2019;12(2):29-39. https://doi.org/10.5829/idosi.aje.2019.29.39. 
311 of the leaf essential oil of Curcuma longa (var. Ch-66) on three species of stored-product beetles

312 (Coleoptera). J. Econ. Entomol. 2002;95:183-189. https://doi.org/10.1603/0022-0493-95.1.183.

313 34. Kim SW, Kang J, Park IK. Fumigant toxicity of Apiaceae essential oils and their constituents

314 against Sitophilus oryzae and their acetylcholinesterase inhibitory activity. J Asia Pac Entomol.

315 2013;16:443-448. https://doi.org/10.1016/j.aspen.2013.07.002.

316 35. López MD, Jordán MJ, Pascual-Villalobos MJ. Toxic compounds in essential oils of

317 coriander, caraway and basil active against stored rice pests. J Stored Prod Res. 2008;44:273-278.

318 https://doi.org/10.1016/j.jspr.2008.02.005.

319 36. Buescher MD, Rutledge LC, Wirtz RA, Nelson JH. The dose-persistence relationship of

320 DEET against Aedes aegypti. Mosquito News. 1983;43:364-366.

321 37. Buczek A, Bartosik K, Kuczyński P. Sensitivity to permethrin in a Dermacentor reticulatus

322 population from eastern Poland in laboratory study. Parasites\&Vectors. 2014;7:18. https://doi:

$323 \quad 10.1186 / 1756-3305-7-18$.

\section{$325 \quad$ Figure legends}

326 Fig.1 Repellency of Sitophilus oryzae caused by caraway essential oil $(* 0.05>\mathrm{p}>0.01 ; * * 0.01$

$327>\mathrm{p}>0.001 ; * * * 0.001>\mathrm{p}>0.0001 ; \mathrm{NS}-$ lack of significant differences; the figure indicates the 328 mean of SE - standard error).

329 Fig.2 Repellency of Sitophilus oryzae caused by L-carvone $(* 0.05>\mathrm{p}>0.01 ; * * 0.01>\mathrm{p}>$ $330 \quad 0.001 ; * * * 0.001>\mathrm{p}>0.0001 ; \mathrm{NS}-$ lack of significant differences; the figure indicates the mean 331 of SE).

332 Fig.3 Mortality of Sitophilus oryzae caused by caraway essential oil (the figure indicates the 333 mean of SE). 
Figures

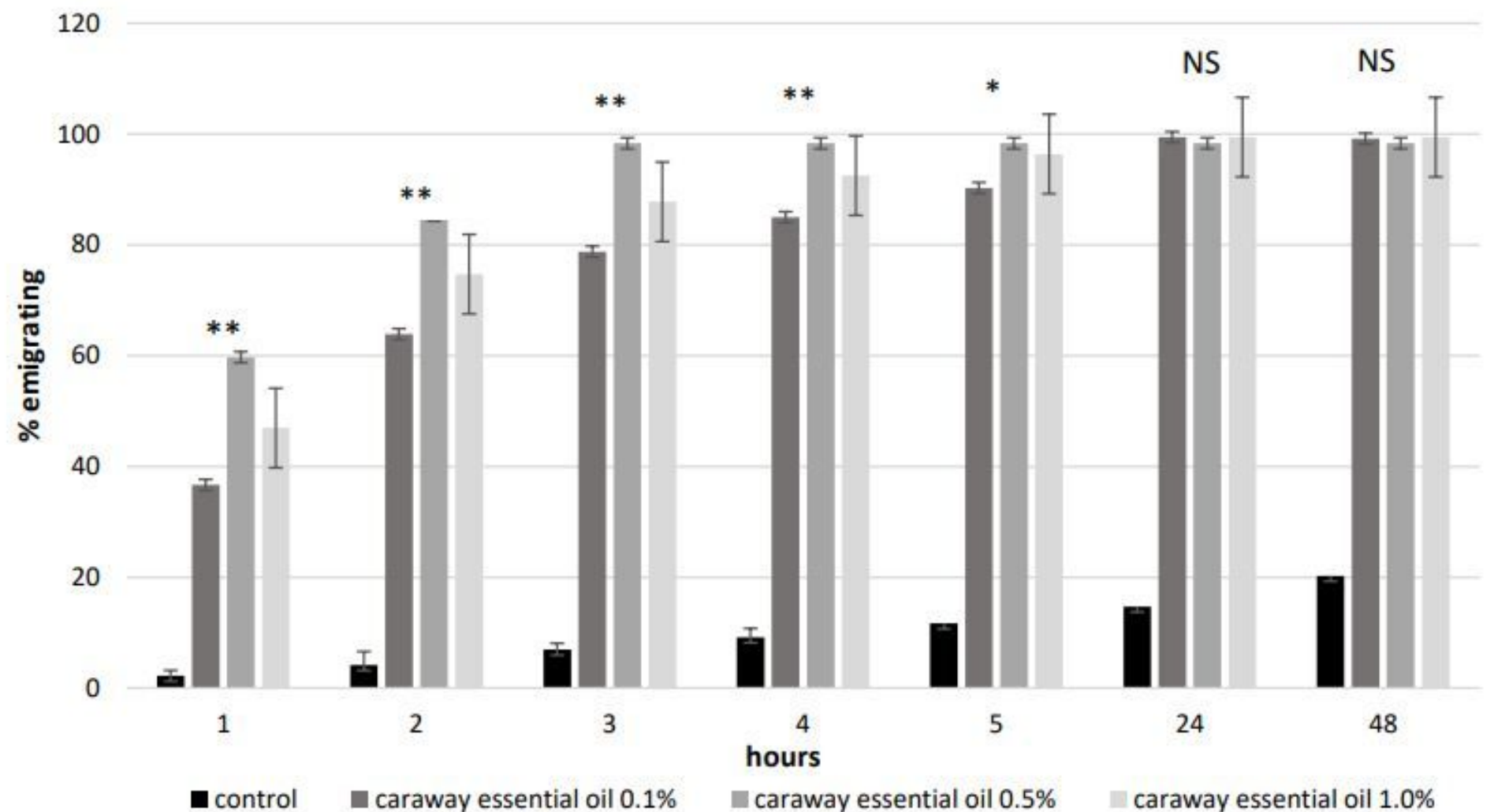

Figure 1

Repellency of Sitophilus oryzae caused by caraway essential oil $(* 0.05>p>0.01 ; * \star 0.01>p>0.001$; $* \star \star$ $0.001>p>0.0001$; NS - lack of significant differences; the figure indicates the mean of SE - standard error). 


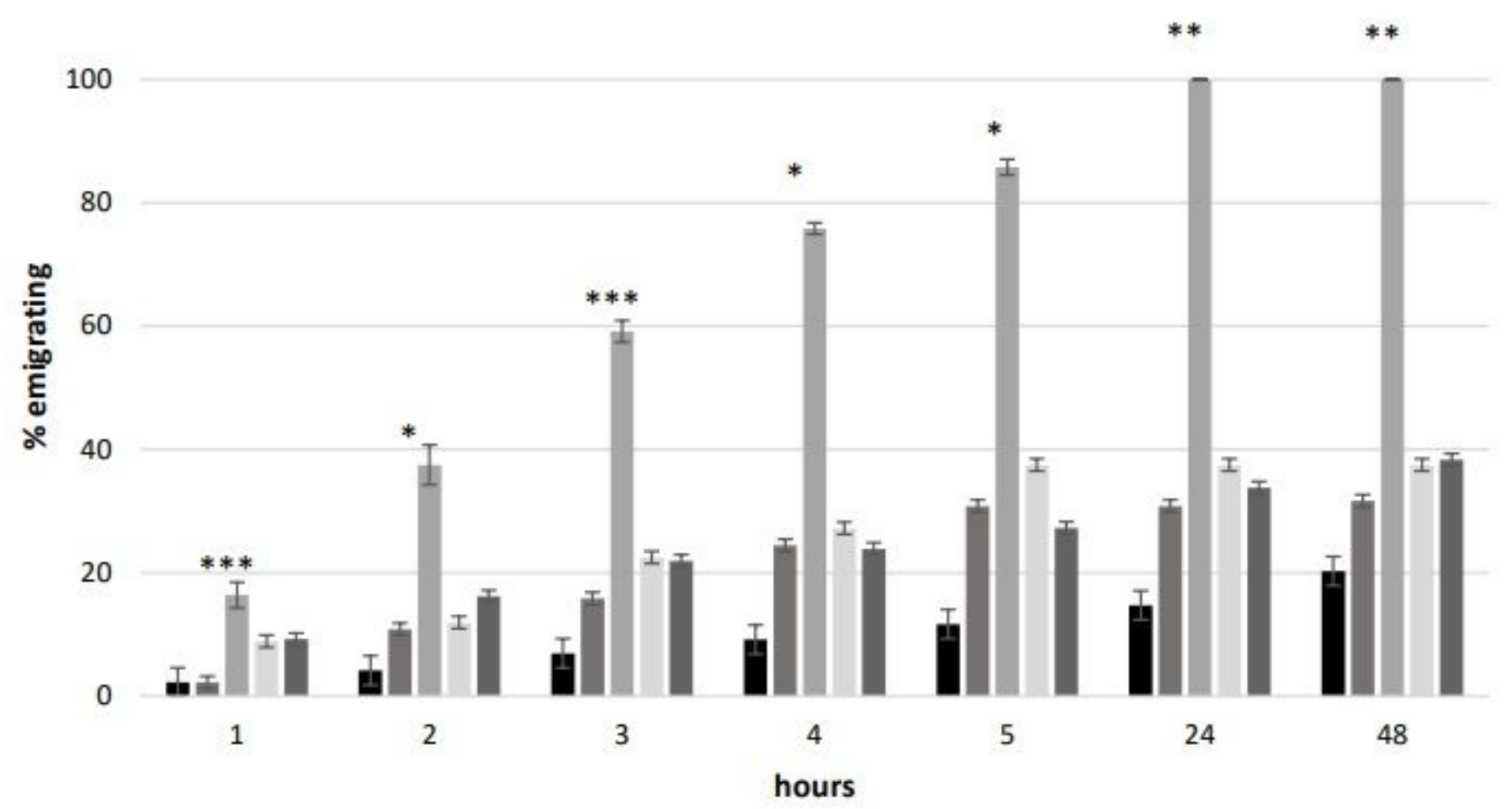

- control $=$ L-carvone $0.05 \%$ - L-carvone $0.1 \%$ L-carvone $0.5 \%$ L-carvone $1.0 \%$

Figure 2

Repellency of Sitophilus oryzae caused by L-carvone $(* 0.05>p>0.01 ; * \star 0.01>p>0.001 ; * \star \star 0.001>p>$ 0.0001 ; NS - lack of significant differences; the figure indicates the mean of SE).

120

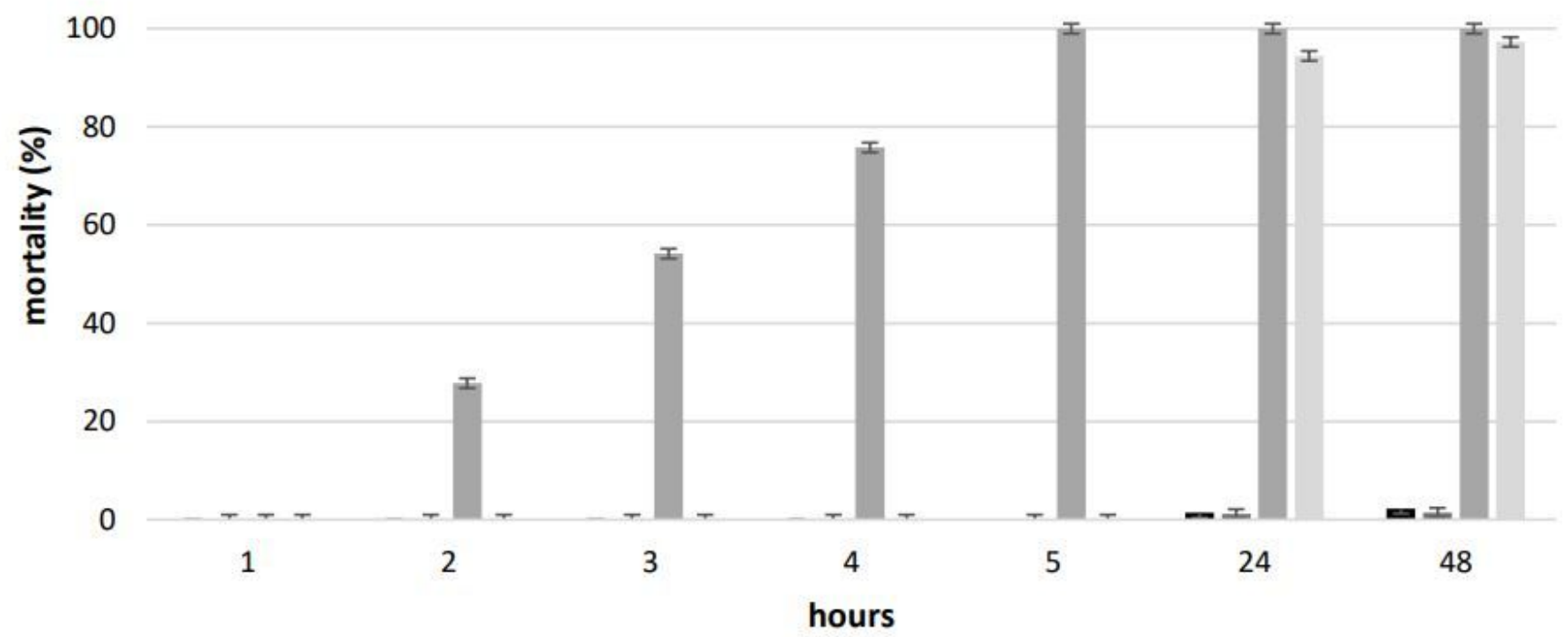

- control a caraway essential oil $0.1 \%$ - caraway essential oil $0.5 \%$ caraway essential oil $1.0 \%$ 
Figure 3

Mortality of Sitophilus oryzae caused by caraway essential oil (the figure indicates the mean of SE). 